\title{
Investigation into buckling coefficients of plates with holes considering variation of hole size and plate thickness
}

\author{
B. Mohammadzadeh*, H.C. Noh** \\ *Dept. of Civil and Environmental Engineering, Sejong University, Seoul, Korea, E-mail: Behzad.alb@gmail.com \\ **Dept. of Civil and Environmental Engineering, Sejong University, Seoul, Korea, E-mail: Cpebach@sejong.ac.kr \\ cross $^{\text {ref }}$ http://dx.doi.org/10.5755/j01.mech.22.3.12767
}

\section{Introduction}

Plates are widely used as one of key components in the various structures such as vehicles, containment structures, spacecrafts and so on. Sometimes depending on requirements, it is needed to make holes in plates, web and flanges of structures or functional systems such as space vehicle, building, water tank piping systems, electrical cables, irrigating system gates and so on [1]. Opening may also be made to accommodate a transverse member, structural or non-structural, in any kind of structures [2]. The presence of holes in plates will change the strength and stiffness of the plate, so the amounts of stress and their distribution which induce the change in the load bearing capacity of the plate, are different from those of plates without holes [3, 4].

The theoretical buckling stress of a flat structural element is the stress at which an exchange of stable equilibrium configurations occurs between the straight and the slightly bent forms [5]. It marks the region in which continued application of load results in accelerated growth of deflections perpendicular to the plane of plates. Its importance lies in the fact that buckling initiates the physical processes which lead to eventual failure of the plate [6]. When a plate element is subjected to direct compression, bending, shear, or a combination of these stresses in its plane, the plate may buckle locally before the member as a whole becomes unstable or before the yield stress of the material is reached. Generally, no attention is paid to the buckling of plates subjected to tensile loads. However, when a plate has a hole, the compressive stress arises near the hole even under a tensile load, and the stress may cause local buck-ling of the plate [7]. Local buckling behavior is characterized by distortion of the cross-section of the member [8]. The theoretical or elastic critical local bucking load is not a satisfactory basis for design. Ultimate strength of plates may be less than the critical local buckling load due to yielding, or may exceed the critical local buckling loads.

The mathematical solution of particular buckling problems requires that equilibrium and boundary conditions to be satisfied. This can be accomplished by integration of the equilibrium partial differential equation of the flat plate or by use of mathematical methods which may not completely satisfy the boundary or equilibrium conditions [9]. The former solutions are exact whereas the methods based generally on energy integrals are approximate although usually very accurate. The need for approximate methods arises from the fact that exact solutions can be found for only a limited number of buckling problems of practical importance [6].

As an alternative several studies investigated the buckling of plates with or without holes from various aspects. Husam Al Qablan et al. [7] investigated the buckling behavior of composite plates with hole subjected to in-plane shear. The results showed that, in the case of shear loading compared to uniaxial and biaxial compression, there is significant reduction in the buckling load by increasing the size of holes. For relatively small size cutouts, a better performance has been achieved if the cutout was kept close to the edge of the plate. For a relatively large size of cutout, however, a higher buckling load was achieved if the cutout was kept in the middle of the plate.

Khaled M. El-sawy and Aly S.Nazmy [10], assessed the effects of aspect ratio (ratio of length a to width b) on the plate buckling load. Two shapes of perforation, circular and rectangular with curved corners, with various location of center of the hole are considered to evaluate the buck-ling load. Results showed that the use of a rectangular hole, with curved corners, with its short dimension positioned along the longitudinal direction of the plate is a better option than using a circular hole, from the plate stability point of view.

Mitao Ohga et al. [11], presented an analytical procedure for the elastic buckling problems of thin-walled members with variable-thickness cross sections. They used Fourier series expansions in the longitudinal direction and numerical integration in the lateral direction to obtain transfer matrix for calculating buckling loads. In their study, end boundary conditions were considered to be restricted whereas the effects of yielding and initial imperfection were neglected.

R. Curtis and R. Till [12], through a study performed in the University of Michigan, calculated the critical buckling stress for plates with one free edge under combined axial and flexural forces. They used energy method to develop equations to find the critical buckling load. Developed equations are applicable to rectangular plates with any length to wide ratio and also to any combination of linearvarying stress. Because of wide use of plates and the importance of buckling as a reason of failure of plates, the current research deals with analyzing the buckling of plate having two holes to find the buckling coefficients correspond to different conditions. Theses coefficients are used to calculate the critical stresses and buckling loads of desired plates. This study not only investigates the effects of creating holes in plates but also finds how the thickness change affects the load carrying capacity of the plate. To this aim, various sizes of holes are taken into account. Diameters of holes are changed in a range from 10 to $70 \mathrm{~mm}$ while the thicknesses of plates are considered to be 1,2, 5 and $10 \mathrm{~mm}$. To analyze the effects of thickness of the plate on buckling loads, the thickness variation from 0.5 to $10 \mathrm{~mm}$ is considered while 
the holes having the diameter of $20 \mathrm{~mm}$ exist in the plate. Besides, the buckling of plate without holes is also investigated, for both viewpoints of thickness and size of hole, to provide a means of comparison between two states of plates with and without holes.

\section{Buckling coefficient}

The solution of Gerard and Becker is inconvenient to write in closed form [13]. The general buckling stress $\sigma_{c r}$ is defined as follows:

$$
\sigma_{c r}=\eta \bar{\eta} \frac{K \pi^{2} E}{12\left(1-v^{2}\right)}\left(\frac{t}{a}\right)^{2}
$$

where $K$ is the buckling coefficient; $\eta$ plasticity factor; $\bar{\eta}$ is cladding reduction factor; $v$ is elastic Poisson's ratio; $t$ is thickness of plate and $a$ is the length of loaded edge in uniaxial compression. In order to simplify above equation and for more convenient calculation, buckling coefficient $K_{C}$, is defined by multiplying three coefficients, $\eta, \bar{\eta}$ and $k$, so Eq. (1) expressing critical buckling stress $\sigma_{c r}$, can be rewritten defined as follows:

$$
\sigma_{c r}=\frac{K_{C} \pi^{2} E}{12\left(1-v^{2}\right)}\left(\frac{t}{a}\right)^{2} .
$$

\section{Modeling of plates}

This study investigates buckling of plate with through-thickness holes to find buckling coefficient $K_{C}$. Because of multi-functional application of these plates, two holes are considered in the plates to be simulated using ABAQUS from buckling point of view. A geometric parameter $\alpha$ is introduced as the ratio of diameter of the hole to the plate width, $\alpha=d / a$, for which critical values for various states will be determined using buckling analysis. This ratio states that for specific conditions and plate dimensions what size of hole is permitted to be perforated in the plate. The plate materials are considered to be of steel with Poisson's ratio of 0.3 , modulus of elasticity of $209 \mathrm{GPa}$ and yield stress of $400 \mathrm{MPa}$, for all the cases that are considered in this study for which the buckling analyses are performed for the following conditions.

\subsection{Plates with different size of holes}

To investigate the effects of the size of holes on the buckling of plate, different sizes of holes are considered to be implemented in plates. A range of diameters from 10 to $70 \mathrm{~mm}$ are used to evaluate the buckling load of plate with holes. To apply boundary conditions on plate, this study considers constraint on the left edge of the plate for displacements in all directions while other edges are constrained for displacement in direction 3, towards out of plane of the plate. Two states of thin and thick plates are considered such that the values of 1 and $2 \mathrm{~mm}$ are assigned to the thin plates while 5 and $10 \mathrm{~mm}$ are considered to be assigned to the thick plates. Holes centers are located at $x=-50 \mathrm{~mm}, y=0 \mathrm{~mm}$ and $x=50 \mathrm{~mm}$, $y=0 \mathrm{~mm}$ for left hole and right hole, respectively. The compressive axial load of $1.0 \mathrm{~N} / \mathrm{m}$ is applied to the right edge of plates. Fig. 1 shows various states of plates with different size of holes having diameter from 10 to $70 \mathrm{~mm}$.

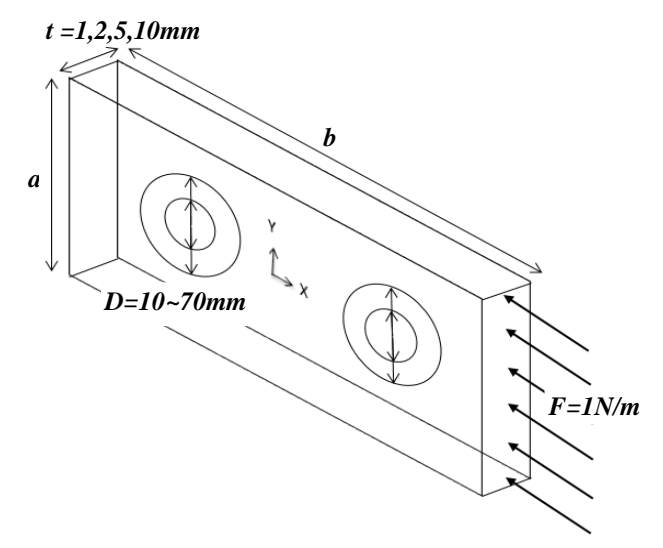

Fig. 1 Variation of hole diameters from 10 to $70 \mathrm{~mm}$

\subsection{Plates with different thickness}

In this pat references [14] and [15] are used. In order to investigate the effects of thickness on buckling of throughthickness hole plates, a range of various thicknesses from 0.5 to $10 \mathrm{~mm}$ is considered. For thin plates the values of thicknesses ranged between 0.5 and $2.5 \mathrm{~mm}$ such that the thickness varies by the value of 0.25 consequently. Plates having the thicknesses from 3 to $10 \mathrm{~mm}$ are ranged as thick plates such that values of thicknesses differ by $1 \mathrm{~mm}$ through this range. The left edge of plate is constrained for displacement in all directions i.e., directions 1, 2 and 3 while for other edges only the displacement in direction 3, out of plane direction, is constrained. Centers of left and right holes of diameter of $20 \mathrm{~mm}$ are located at coordinates of $x=-50 \mathrm{~mm}, y=0 \mathrm{~mm}$ and $x=50 \mathrm{~mm}, y=0 \mathrm{~mm}$, respectively. A distributed load of magnitude $1.0 \mathrm{~N} / \mathrm{m}$ is applied in a compressive direction on the right edge of the plate (Fig. 2).

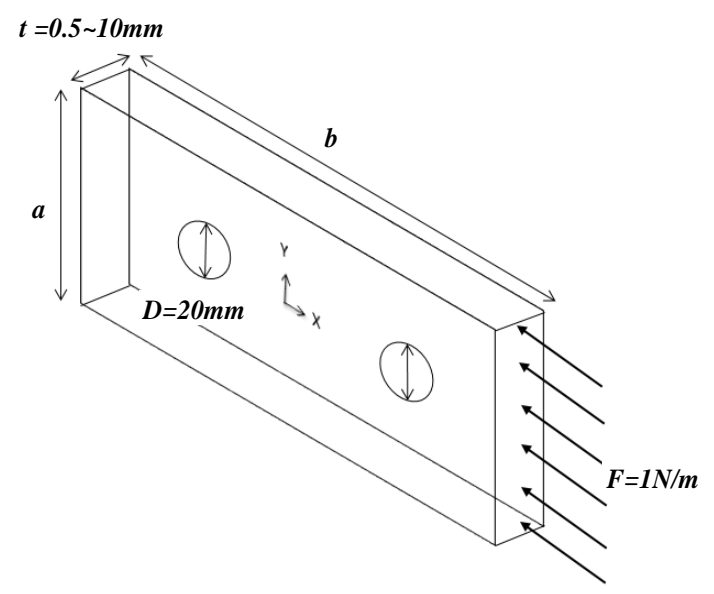

Fig. 2 Schematic of plates having variation in thicknesses

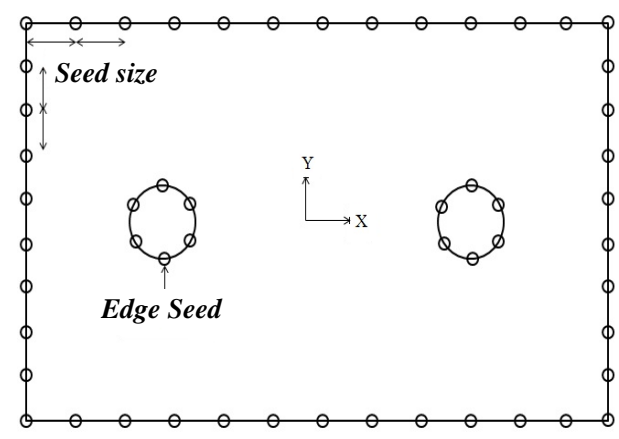

Fig. 3 Seed size in plates 
In order to mesh the plate, a quadratic 8-Node second order element is used. This element uses the reduced integration to improve the solution and to eliminate the locking phenomenon. Approximate global size of seeds, determining the size of mesh, is considered to have the value of 0.02 (Fig. 3).

In order to provide a mean of comparing the buckling stresses of plates having holes with those of plate without holes as well as making comparison between buckling coefficients of plate with and without holes, this study also models and analyzes plates without holes for the range of thickness as already used for plates with holes. Plates with same dimension and properties but without holes are simulated. By having the results of these simulations, it is possible to investigate the effect of perforating holes in the plate as well as to calculate the amounts of decrease or increase in buckling loads or buckling coefficients under different conditions.

\section{Numerical investigation}

The buckling analyses of plate with through-thickness holes are performed to find the critical load and buckling coefficients of plates having holes with respect to plate thickness and diameter of hole. The main aim is to generalize the results to propose appropriate criteria for designing the plates having hole from the viewpoint of buckling. A dimensionless geometric parameter $\alpha=d / a$, a kind of aspect ratio, is considered here to generalize the results of the critical buckling loads and buckling coefficients.

Table 1

Critical loads and stresses of plates with various thicknesses with respect to $\alpha$

\begin{tabular}{|c|c|c|c|c|c|c|c|c|c|c|}
\hline \multirow[b]{2}{*}{ NO } & \multirow{2}{*}{$\begin{array}{c}\text { Diameter, } \\
\mathrm{mm}\end{array}$} & \multirow{2}{*}{$\begin{array}{c}\alpha \\
d / a\end{array}$} & \multicolumn{2}{|c|}{$\begin{array}{l}\text { Thickness } \\
(1 \mathrm{~mm})\end{array}$} & \multicolumn{2}{|c|}{$\begin{array}{l}\text { Thickness } \\
(2 \mathrm{~mm})\end{array}$} & \multicolumn{2}{|c|}{$\begin{array}{l}\text { Thickness } \\
(5 \mathrm{~mm})\end{array}$} & \multicolumn{2}{|c|}{$\begin{array}{l}\text { Thickness } \\
(10 \mathrm{~mm})\end{array}$} \\
\hline & & & $\begin{array}{c}\text { Critical } \\
\text { load, } \\
\text { kN }\end{array}$ & $\begin{array}{c}\text { Critical } \\
\text { stress, } \\
\text { MPa }\end{array}$ & $\begin{array}{c}\text { Critical } \\
\text { load, } \\
\mathrm{kN}\end{array}$ & $\begin{array}{l}\text { Critical } \\
\text { stress, } \\
\text { MPa }\end{array}$ & $\begin{array}{c}\text { Critical } \\
\text { load, } \\
\text { kN }\end{array}$ & $\begin{array}{c}\text { Critical } \\
\text { stress, } \\
\mathrm{MPa}\end{array}$ & $\begin{array}{c}\text { Critical } \\
\text { load, } \\
\text { kN }\end{array}$ & $\begin{array}{c}\text { Critical } \\
\text { stress, } \\
\mathrm{MPa}\end{array}$ \\
\hline 1 & 10 & 0.1 & 7.18 & 71.80 & 56.68 & 283.43 & 864.40 & 1728.80 & 6544.50 & 6544.50 \\
\hline 2 & 20 & 0.2 & 6.74 & 67.41 & 53.34 & 266.60 & 806.75 & 1613.50 & 6171.80 & 6171.80 \\
\hline 3 & 30 & 0.3 & 6.42 & 64.20 & 50.82 & 254.10 & 780.00 & 1560.00 & 5880.00 & 5880.00 \\
\hline 4 & 40 & 0.4 & 6.31 & 63.09 & 49.80 & 249.00 & 753.40 & 1506.80 & 5790.00 & 5790.00 \\
\hline 5 & 50 & 0.5 & 6.25 & 62.50 & 49.30 & 246.50 & 750.00 & 1500.00 & 5663.00 & 5663.00 \\
\hline 6 & 60 & 0.6 & 5.97 & 59.71 & 47.30 & 236.50 & 720.00 & 1440.00 & 5500.00 & 5500.00 \\
\hline 7 & 70 & 0.7 & 5.44 & 54.35 & 42.70 & 213.50 & 653.00 & 1306.00 & 4920.00 & 4920.00 \\
\hline
\end{tabular}

\subsection{Effect of hole size}

Table 1 shows the resulting buckling loads and stresses obtained for plates with holes having thicknesses of $1 \mathrm{~mm}, 2,5$ and $10 \mathrm{~mm}$. As it is observable from Table 1, the obtained critical buckling loads of plates having thicknesses of 5 and $10 \mathrm{~mm}$ lead to stresses greater than the permissible yielding stress of steel which, in this study, is $400 \mathrm{MPa}$. As the hole size increases, the amount of buckling load (critical load) decreases. For each thickness, the maximum buckling load is obtained for the plate with smallest hole while the largest hole will result in the smallest critical load. It is worthy to note that the smaller the thickness the smaller the load carrying capacity. To provide better understanding of buckling phenomenon happened to the plate, the buckled shapes of plates of $\alpha=0.2$ and 0.6 are given in Fig. 4 .

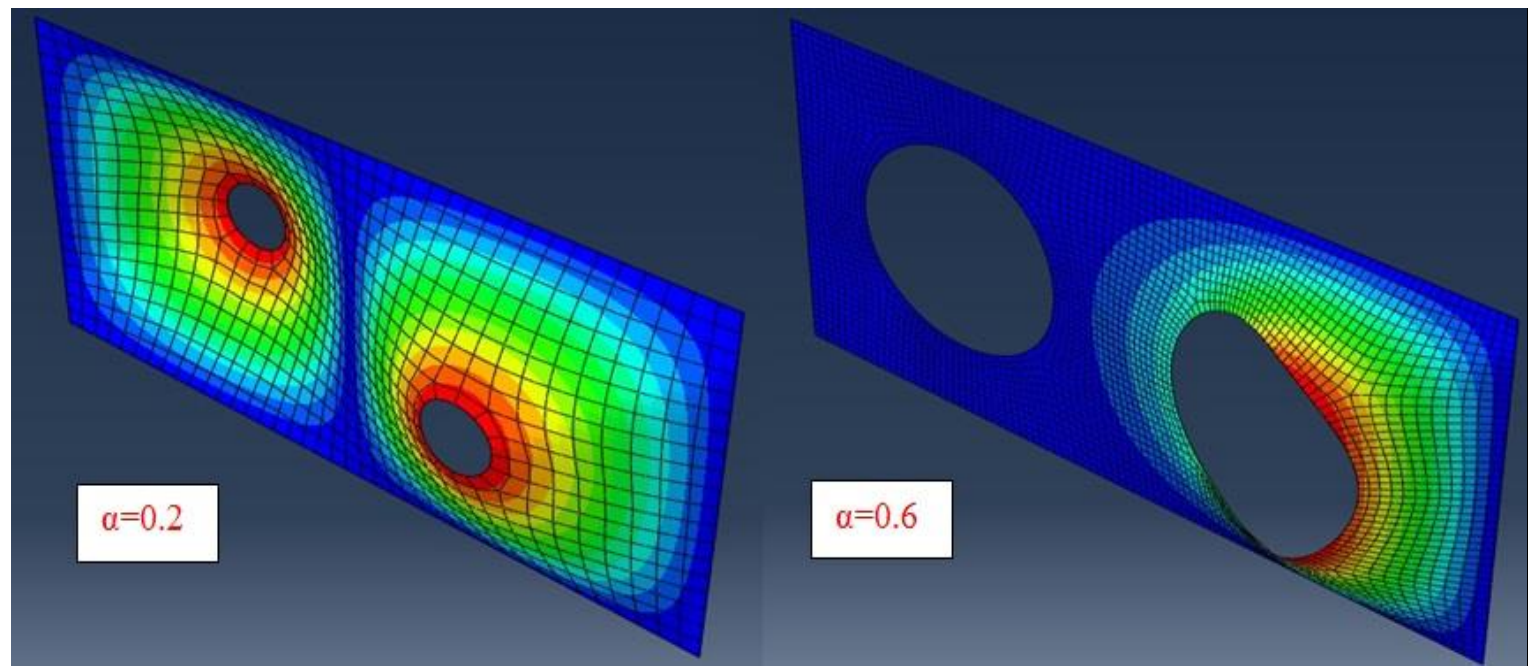

Fig. 4 Buckled shape of plate of thickness of $5 \mathrm{~mm}$ for $\alpha=0.2$ and $\alpha=0.6$ (Mode I)

In order to find critical stress by which the critical load is computed, buckling coefficients $K_{C}$ are defined and calculated. As Eq. (2) shows, $K_{C}$ relates the buckling stress to dimensions of plate. Therefore, in designing plates with desired dimensions and holes, it is possible to calculate the buck- ling stresses and buckling loads by using buckling coefficients.

Figs. 5, a and $b$ show variation of buckling loads in terms of varying $\alpha$, for plates having holes of thickness 1 and $2 \mathrm{~mm}$, respectively. By increasing the size of holes the 
amounts of critical loads nonlinearly decrease. The rate of decrease in buckling load varies with respect to changes in $\alpha$. As can be seen from the graphs we can reliably choose any size of hole in range from 0.3 to 0.5 no matter the change in buckling load.

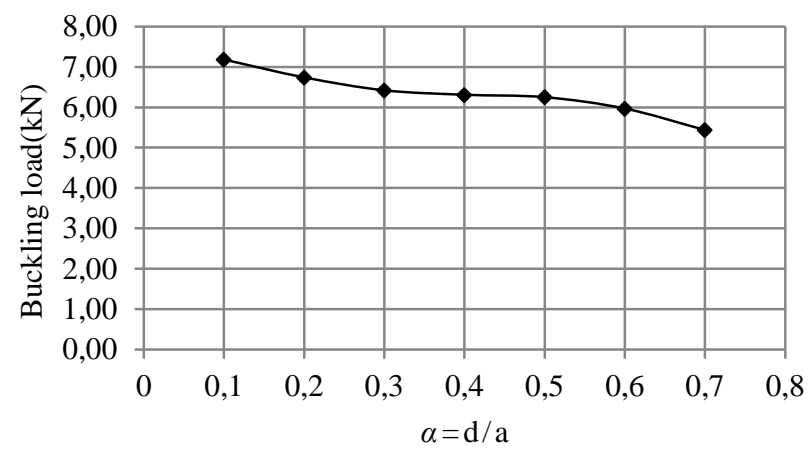

a

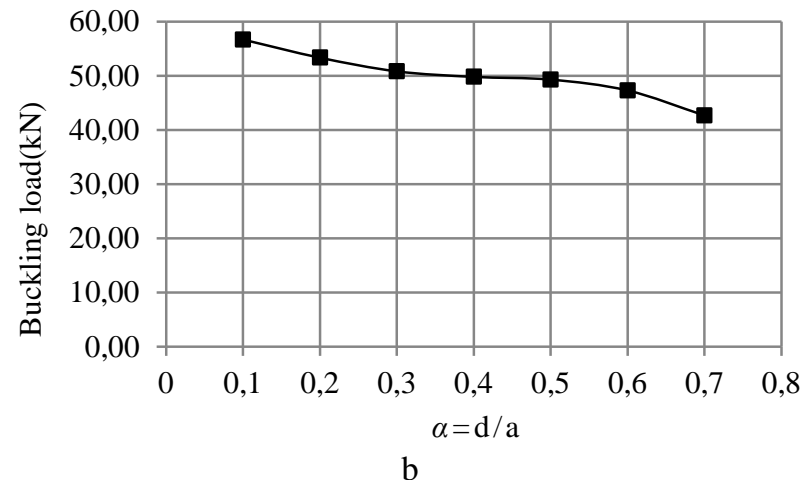

Fig. 5 Change in buckling load for thin plates with respect to $\alpha$ : a - plate of $1 \mathrm{~mm}$ thickness; $\mathrm{b}$ - plate of $2 \mathrm{~mm}$ thickness

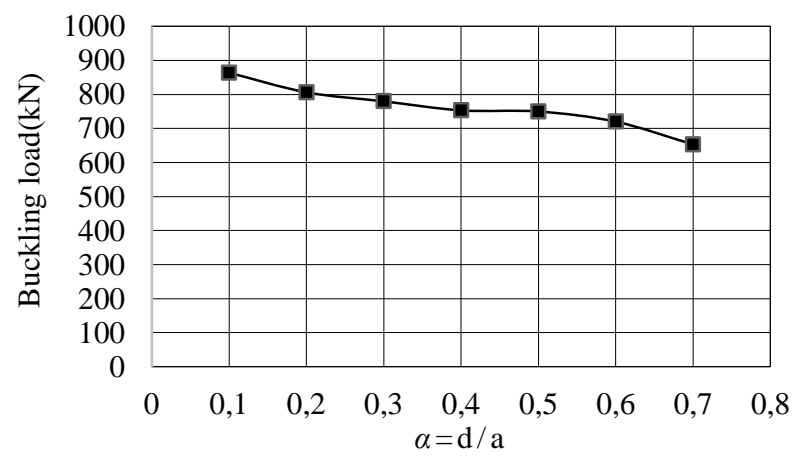

a

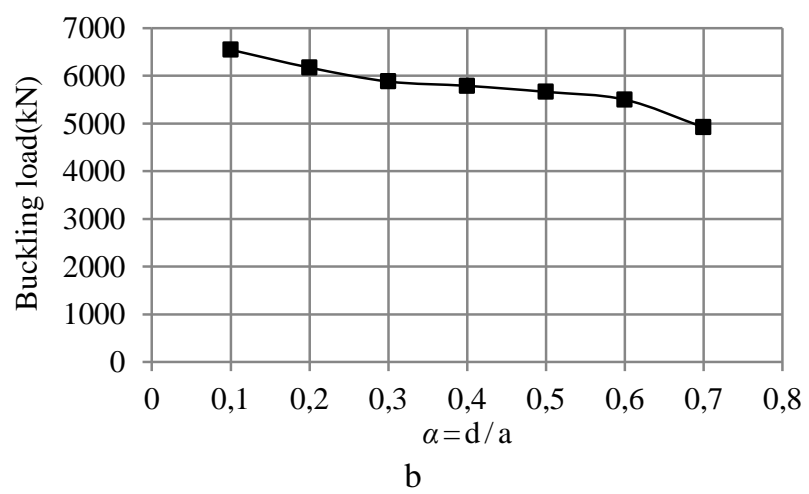

Fig. 6 Change in buckling load for thick plates thickness with respect to $\alpha$ : a - plate of $5 \mathrm{~mm}$ thickness; b - plate of $10 \mathrm{~mm}$ thickness
The graphs corresponding to critical loads of plates with holes of thickness $5 \mathrm{~mm}$ and $10 \mathrm{~mm}$ are provided in Figs. 6, a and b, respectively. They show the similar trend with those of thin plates. The difference between buckling trend of thin and thick plates is that the amount of decrease in buckling loads for thick plate is more than those of thin plates. The slope of decrease in buckling load for thick plates is steeper than that of thin plates. To illustrate nonlinear trend of decrease in buckling load as for varying $\alpha$, Fig. 7 provides normalized buckling loads with respect to the buckling load corresponding to $\alpha$ of 0.4 .

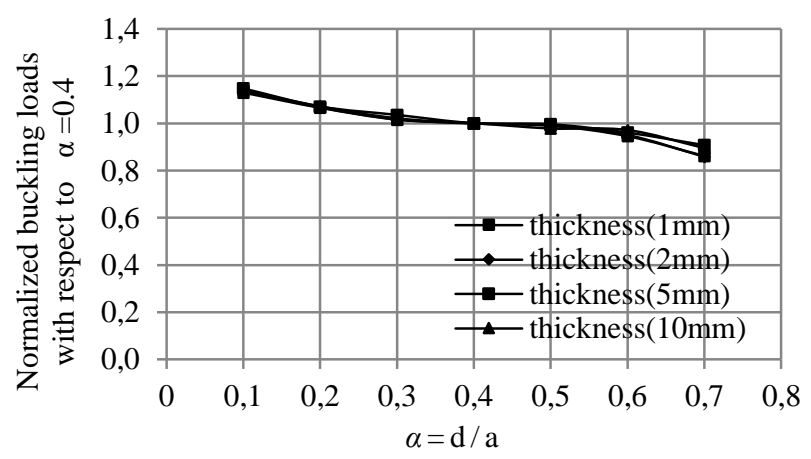

Fig. 7 Normalized buckling loads of thin and thick plates with respect to $\alpha=0.4$

Table 2 shows the value of buckling coefficients $K_{C}$ obtained for both thin and thick plates having different size of holes. As given in Table 2, the effect of size of hole on buckling load is observable. As the ratio $\alpha$ increases the buckling coefficient decreases and so do the critical stresses obtained by using these coefficients. Having buckling coefficients as well as material properties of desired plate and its dimensions, the critical stresses can be computed. It is appropriate to note that the units of buckling stresses calculated using these buckling coefficients are MPa.

Table 2

Buckling coefficients $K_{C}$ for different thicknesses and different $\alpha$

\begin{tabular}{|c|c|c|c|c|c|}
\hline \multirow{2}{*}{ NO } & \multirow{2}{*}{$\begin{array}{c}\alpha \\
(d / a)\end{array}$} & \multicolumn{4}{|c|}{ Buckling Coefficients of plates of various thick- } \\
\cline { 3 - 6 } & & $1 \mathrm{~mm}$ & $2 \mathrm{~mm}$ & $5 \mathrm{~mm}$ & $10 \mathrm{~mm}$ \\
\hline 1 & 0.1 & 3.81 & 3.75 & 3.02 & 2.86 \\
\hline 2 & 0.2 & 3.57 & 3.53 & 2.82 & 2.68 \\
\hline 3 & 0.3 & 3.40 & 3.36 & 2.72 & 2.57 \\
\hline 4 & 0.4 & 3.34 & 3.30 & 2.63 & 2.53 \\
\hline 5 & 0.5 & 3.32 & 3.26 & 2.60 & 2.47 \\
\hline 6 & 0.6 & 3.16 & 3.13 & 2.51 & 2.40 \\
\hline 7 & 0.7 & 2.88 & 2.83 & 2.28 & 2.15 \\
\hline
\end{tabular}

Fig. 8 shows the variations of buckling coefficients $K_{C}$ of both thin and thick plates with respect to different ratio $\alpha$. It can be inferred that their variations are irregular while diameter of the hole changes regularly. As the thickness of the plate increases the buckling coefficients decrease while by increasing in $\alpha$, the buckling coefficients gradually decrease. For $\alpha$, from 0.2 to 0.3 , the buckling coefficients decrease similarly for the range of 0.5 to 0.6 but with reversed curvature. By increasing in $\alpha$ in the range from 0.5 to 0.7 , the rate of decrease in buckling coefficient is much faster than the other ranges, which shows the faster decrease in resistance of plate against 
buckling. After $\alpha=0.6$ a sudden drop is observable in buckling coefficient, therefore it is recommended that not to choose $\alpha$ in this range. Trend of graph for range of $\alpha$ from 0.3 to 0.5 is virtually plateau which demonstrates that critical load is virtually not affected by the varying value of $\alpha$ in this range. This means that the greater hole can be used without decrease in the buckling resistance.

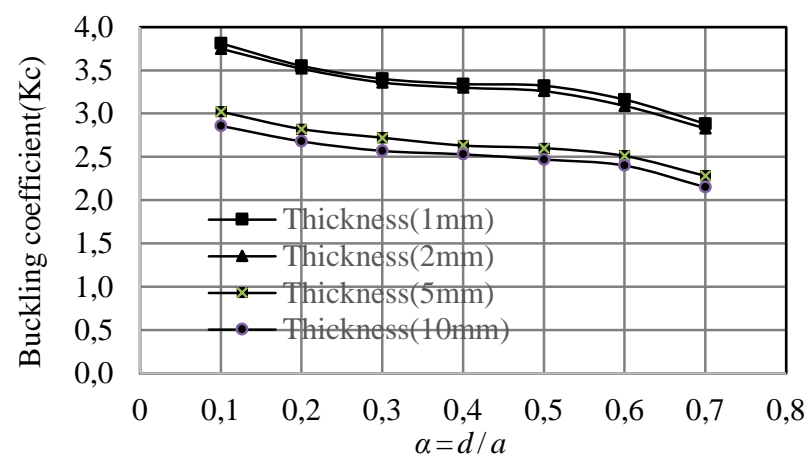

Fig. 8 Buckling coefficient versus hole dimension ratio $\alpha$ $(d / a)$

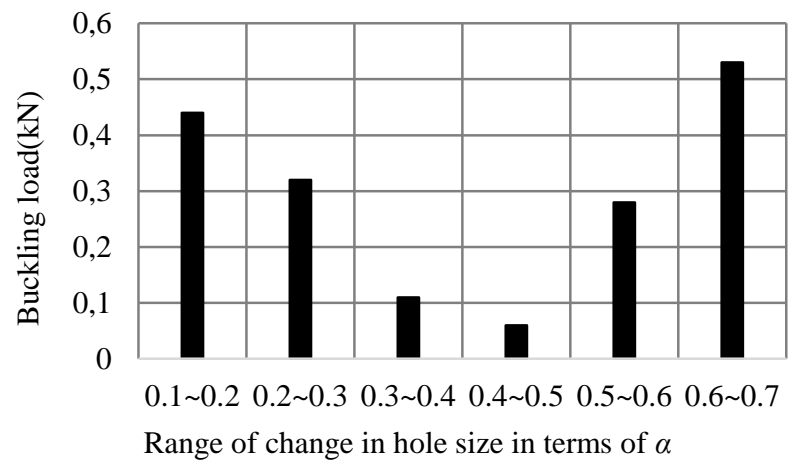

Fig. 9 Variation of buckling loads of plate having thickness of $1 \mathrm{~mm}$ with respect to the changes in size of holes

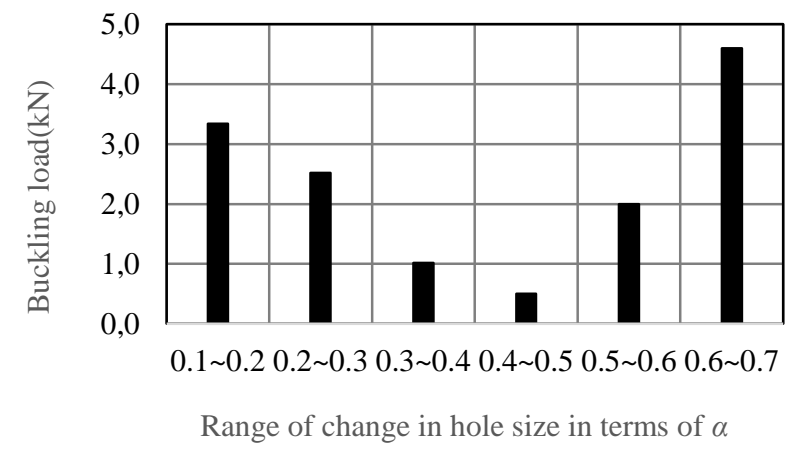

Fig. 10 Variation of buckling loads of plate having thickness of $2 \mathrm{~mm}$ with respect to the changes in size of holes

The variation of buckling loads of desired plates with respect to changes in holes sizes are investigated and presented in Figs. 9 to 12. The Investigation shows that maximum change in buckling loads of thin plates are occurred in the range of diameter from 60 to $70 \mathrm{~mm}$ corresponding to $\alpha=0.6$ and $\alpha=0.7$, respectively. The smallest change in critical load occurred in the range of diameter from 40 to $50 \mathrm{~mm}$, corresponding to $\alpha$ from 0.4 to 0.5 , so it is possible to choose holes having any diameter of this range.
Investigating into the bar graph corresponding to plate having the thickness of $5 \mathrm{~mm}$, it can be found that the maximum change in buckling loads occurred when the diameter of holes change in the range of 6 to $70 \mathrm{~mm}$, i.e., $\alpha$ from 0.6 to 0.7 while the minimum change in buckling load occurs for the range of 40 to $50 \mathrm{~mm}$ related to $\alpha=0.4$ and $\alpha=0.5$, respectively. As the graph given in Fig. 12 shows the maximum change in buckling load of plate of $10 \mathrm{~mm}$ thickness occurred for the range of $\alpha$ from 0.6 to 0.7 while the minimum change has been occurred for range of diameter of $30 \mathrm{~mm}$, $\alpha=0.3$, to $40 \mathrm{~mm}, \alpha=0.4$.

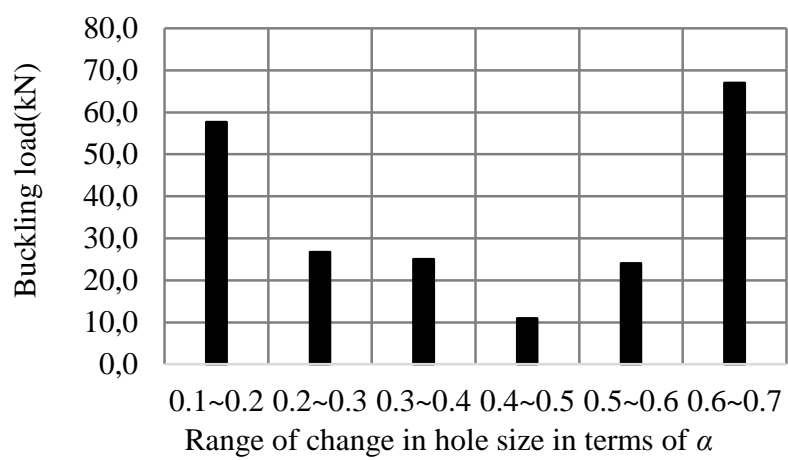

Fig. 11 Variation of buckling loads of plate having thickness of $5 \mathrm{~mm}$ with respect to the changes in size of holes

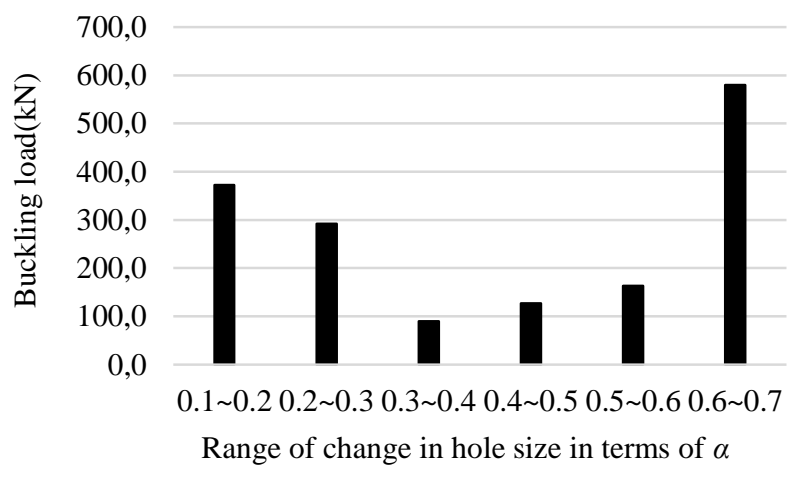

Fig. 12 Variation of buckling loads of plate of $10 \mathrm{~mm}$ thickness with respect to the changes in size of holes

\subsection{Effect of plate thickness}

Analyzing the effects of thickness of plate having through- thickness hole on buckling load was undertaken to find the range of permissible applying load in terms of the thickness. Resultant critical loads and critical stresses of plate with hole, with respect to different values of thickness, as well as those for plate without hole are provided in Table 3.

As given in Table 3, as the thickness of the plate increases, the buckling load increases as expected. However, the trend is nonlinear because the buckling load is proportional to $t^{3}$ approximately while the critical stress is a function of $t^{2}$. If we observe the results, we can find a logical relationship between obtained critical loads for each case and the amount of increase in thickness. It can be written as Eq. (3):

$$
\frac{F_{c r 2}}{F_{c r 1}}=\left(\frac{t_{2}}{t_{1}}\right)^{3} .
$$


The relationship between critical stresses and thicknesses of the plates can be written as Eq. (4):

$$
\frac{\sigma_{c r 2}}{\sigma_{c r 1}}=\left(\frac{t_{2}}{t_{1}}\right)^{2} .
$$

By having buckling coefficient for a plate of thickness of, $t_{1}$ it is possible to approximately calculate the critical load of any desired plate having the thickness of $t_{2}$. It can provide designers a quick view about the desired plate, i.e., they can quickly find out the load carrying capacity of a desired plate.

Table 3

Critical loads and stresses for plates with varying thickness with and without holes [16]

\begin{tabular}{|c|c|c|c|c|c|c|c|}
\hline \multirow{3}{*}{ NO } & \multirow{3}{*}{ Thickness, mm } & \multicolumn{4}{|c|}{ Critical load, kN/m } & \multicolumn{2}{|c|}{ Critical stress, MPa } \\
\hline & & \multicolumn{2}{|c|}{ Plate with hole } & \multicolumn{2}{|c|}{ Plate without hole } & \multirow{2}{*}{$\begin{array}{c}\begin{array}{c}\text { Plate } \\
\text { with hole }\end{array} \\
\text { Values }\end{array}$} & \multirow{2}{*}{$\begin{array}{c}\text { Plate } \\
\text { without hole } \\
\text { Values }\end{array}$} \\
\hline & & Values & $\frac{F_{c r}(i+1) / F_{c r}(i)}{(t(i+1) / t(i))^{3}}$ & Values & $\frac{F_{c r}(i+1) / F_{c r}(i)}{(t(i+1) / t(i))^{3}}$ & & \\
\hline 1 & 0.50 & 8.51 & 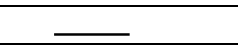 & 9.31 & & 17.02 & 18.62 \\
\hline 2 & 0.75 & 28.38 & 0.988 & 31.10 & 0.990 & 37.84 & 41.47 \\
\hline 3 & 1.00 & 67.41 & 1.002 & 73.98 & 1.003 & 67.41 & 73.98 \\
\hline 4 & 1.25 & 131.60 & 0.999 & 144.60 & 1.001 & 105.28 & 115.68 \\
\hline 5 & 1.50 & 226.40 & 0.995 & 249.00 & 0.996 & 150.93 & 166.00 \\
\hline 6 & 1.75 & 359.05 & 0.998 & 395.20 & 0.999 & 205.17 & 225.83 \\
\hline 7 & 2.00 & 533.38 & 0.995 & 587.42 & 0.996 & 266.69 & 293.71 \\
\hline 8 & 2.25 & 758.96 & 0.999 & 836.30 & 0.999 & 337.32 & 371.69 \\
\hline 9 & 2.50 & $1,037.60$ & 0.996 & $1,143.80$ & 0.997 & 415.04 & 457.52 \\
\hline 10 & 3.00 & $1,782.32$ & 0.994 & $1,966.19$ & 0.994 & 594.11 & 655.40 \\
\hline 11 & 4.00 & $4,179.06$ & 0.989 & $4,615.56$ & 0.990 & 1044.77 & 1153.89 \\
\hline 12 & 5.00 & $8,067.56$ & 0.988 & $8,915.93$ & 0.989 & 1613.51 & 1783.19 \\
\hline 13 & 6.00 & $13,768.50$ & 0.987 & $15,220.50$ & 0.987 & 2294.75 & 2536.75 \\
\hline 14 & 7.00 & $21,578.00$ & 0.987 & $23,853.80$ & 0.987 & 3082.57 & 2707.69 \\
\hline 15 & 8.00 & $31,766.00$ & 0.986 & $35,110.10$ & 0.986 & 3970.79 & 4388.76 \\
\hline 16 & 9.00 & $44,577.00$ & 0.985 & $49,253.10$ & 0.985 & 4953.04 & 5472.57 \\
\hline 17 & 10.00 & $61,718.80$ & 1.009 & $68,170.00$ & 1.009 & 6171.88 & 6817.00 \\
\hline
\end{tabular}

If we apply Eq. (4) to the data of critical stress, we can obtain almost the same values as given in the 4th and 6th columns in Table 3. Buckling loads of plates with and without holes as well as the ratio of critical loads of plate with holes to the plate without holes are provided in Fig. 13. Graph which is given with diamond symbol shows the results of analyses of plates without holes while the graph regarding to plates having holes is given with rectangles. The graph with triangle symbols shows the changes in ratio of buckling loads for plate with holes to that of plate without holes. As can be seen for thin plates, both plates provide buckling loads very close to each other but by increasing the thickness the differences are more considerable as can be seen by the line with triangle symbols. The minimum ratio occurred for the plates having the thicknesses in the range from 5 to $8 \mathrm{~mm}$ for which the maximum decrease in buckling load due to existence of hole is occurred i.e., the maximum difference between buckling loads of plates with and without holes happened for the plates having the thickness in the range.

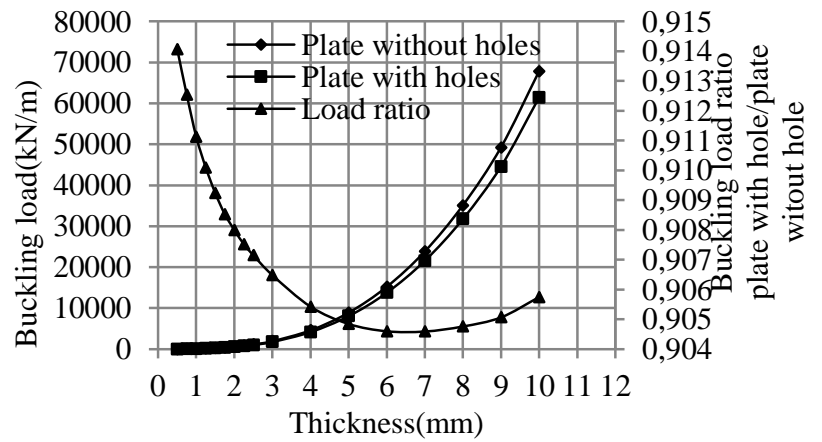

Fig. 13 Comparative graph for buckling loads of plates with and without holes and load ratio versus thickness [16]
The results for critical stresses are provided in Fig. 14. The stresses for both plates with and without holes having the thicknesses from 0.5 to $5 \mathrm{~mm}$ are close to each other but the differences between critical stresses are relatively large for plates of thicknesses from 5 to $10 \mathrm{~mm}$. The graph for critical stress ratio states that the existence of holes in plate has more effect on plates having the thicknesses in the range from 5 to $8 \mathrm{~mm}$ than the other plates.

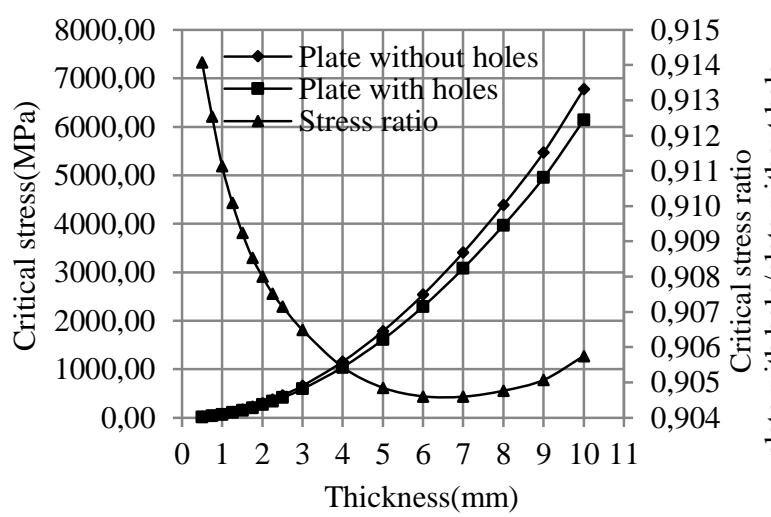

Fig. 14 Comparative graph for critical stresses of plates with and without holes and stress ratio versus thickness [16]

By using the results given in Table 3 , obtained from finite element analyses, the buckling coefficients $K_{C}$, which correspond to $\alpha=0.2$ can be calculated as given in Table 4. The given results for buckling coefficients show that as the thickness increases the buckling coefficients decreases for both plates with and without holes. However, as 
the thickness directly affects the critical stress, as given in Eq. (2), therefore the obtained buckling coefficients corresponding to thicker plates will definitely provide larger va- lues of buckling load and stresses. Plates with holes provide smaller buckling coefficients having ratio of approximately 0.91 irrespective of the plate thickness.

Table 4

Buckling coefficient for different thicknesses $\alpha=0.2$ [16]

\begin{tabular}{|c|c|c|c|c|}
\hline \multirow{2}{*}{ NO } & \multirow{2}{*}{$\begin{array}{c}\text { Thickness, } \\
\mathrm{mm}\end{array}$} & \multicolumn{2}{|c|}{$K_{C}$} & \multirow{2}{*}{$K_{C}($ Hole $)$} \\
\cline { 3 - 4 } & & $\begin{array}{c}\text { Plate } \\
\text { with hole }\end{array}$ & $\begin{array}{c}\text { Plate } \\
\text { without hole }\end{array}$ & $K_{C}($ No-Hole $)$ \\
\hline 1 & 0.50 & 3.604 & 3.943 & 0.91 \\
\hline 2 & 0.75 & 3.594 & 3.938 & 0.91 \\
\hline 3 & 1.00 & 3.574 & 3.923 & 0.91 \\
\hline 4 & 1.25 & 3.567 & 3.919 & 0.91 \\
\hline 5 & 1.50 & 3.551 & 3.906 & 0.91 \\
\hline 6 & 1.75 & 3.547 & 3.904 & 0.91 \\
\hline 7 & 2.00 & 3.530 & 3.887 & 0.91 \\
\hline 8 & 2.25 & 3.468 & 3.822 & 0.91 \\
\hline 9 & 2.50 & 3.245 & 3.577 & 0.91 \\
\hline 10 & 3.00 & 2.880 & 3.177 & 0.91 \\
\hline 11 & 4.00 & 2.849 & 3.147 & 0.91 \\
\hline 12 & 5.00 & 2.816 & 3.112 & 0.91 \\
\hline 13 & 6.00 & 2.781 & 3.074 & 0.91 \\
\hline 14 & 7.00 & 2.745 & 3.034 & 0.91 \\
\hline 15 & 8.00 & 2.707 & 2.992 & 0.91 \\
\hline 16 & 9.00 & 2.668 & 2.948 & 0.91 \\
\hline 17 & 10.00 & 2.680 & 2.959 & 0.91 \\
\hline
\end{tabular}

4.3. Verification of generality of $K_{C}$ : Check with different-size plates

In order to investigate the generality of buckling coefficients for plates having different dimensions from those used in this study, we analyze the plates with width of $200 \mathrm{~mm}$ and length of $400 \mathrm{~mm}$ having the same thicknesses and $\alpha$ with the example plates. To investigate the buckling coefficients from viewpoints of plate thickness and holes size, four states are chosen. Two different thicknesses of 1 and $2 \mathrm{~mm}$ corresponding to thin plates and other two of 5 and $10 \mathrm{~mm}$ corresponding to thick plates are considered while different diameters of holes are chosen such that the hole dimension ratios are $\alpha=0.1, \alpha=0.3, \alpha=0.5$ and $\alpha=0.7$. After modeling the plates using ABAQUS and obtaining the eigenvalues, the critical stresses are calculated.

Then the theoretical critical stresses are calculated by using the presented buckling coefficients in Table 2 and Eq. (2). Thereafter the results obtained from ABAQUS models and those calculated by buckling coefficients are compared and the errors are calculated. The results are provided in Table 5.

Comparative table obtained for verifying obtained buckling coefficients

Table 5

\begin{tabular}{|c|c|c|c|c|c|c|c|c|}
\hline \multirow[b]{2}{*}{$\mathrm{NO}$} & \multirow{2}{*}{$\begin{array}{c}\text { Thickness, } \\
\text { mm }\end{array}$} & \multicolumn{3}{|c|}{ Results of ABAQUS } & \multicolumn{4}{|c|}{ Results obtained by using $K c$} \\
\hline & & $\alpha=d / a$ & Eigenvalues & $\begin{array}{c}\text { Critical load, } \\
\mathrm{N} \\
\end{array}$ & $\begin{array}{c}\text { Buckling } \\
\text { stress, MPa }\end{array}$ & $K_{C}$ & $\begin{array}{c}\text { Buckling } \\
\text { stress, MPa }\end{array}$ & $\begin{array}{c}\text { Error, } \\
\%\end{array}$ \\
\hline 1 & \multirow{4}{*}{$t=1$} & 0.10 & $18,014.00$ & $3,602.80$ & 18.01 & 3.81 & 17.99 & -0.133 \\
\hline 2 & & 0.30 & $16,061.00$ & $3,212.20$ & 16.07 & 3.40 & 16.05 & -0.124 \\
\hline 3 & & 0.50 & $15,782.00$ & $3,156.40$ & 15.78 & 3.32 & 15.66 & -0.773 \\
\hline 4 & & 0.70 & $13,776.00$ & $2,755.20$ & 13.78 & 2.88 & 13.61 & -1.205 \\
\hline 5 & \multirow{4}{*}{$t=2$} & 0.10 & $144,000.00$ & $28,800.00$ & 72.00 & 3.75 & 70.84 & -1.611 \\
\hline 6 & & 0.30 & $128,000.00$ & $25,600.00$ & 64.00 & 3.36 & 63.43 & -0.891 \\
\hline 7 & & 0.50 & $125,000.00$ & $25,000.00$ & 62.50 & 3.26 & 61.62 & -1.408 \\
\hline 8 & & 0.70 & $109,000.00$ & $21,800.00$ & 54.50 & 2.83 & 53.46 & -1.908 \\
\hline 9 & \multirow{4}{*}{$t=5$} & 0.10 & $2,210,000.00$ & $442,000.00$ & 442.00 & 3.02 & 433.58 & -1.905 \\
\hline 10 & & 0.30 & $2,002,000.00$ & $400,400.00$ & 400.40 & 2.72 & 393.06 & -1.833 \\
\hline 11 & & 0.50 & $1,870,000.00$ & $374,000.00$ & 374.00 & 2.60 & 372.15 & -0.495 \\
\hline 12 & & 0.70 & $1,635,000.00$ & $327,000.00$ & 327.00 & 2.28 & 325.82 & -0.361 \\
\hline 13 & \multirow{4}{*}{$t=10$} & 0.10 & $16,700,000.00$ & $33,400,000.00$ & $1,670.00$ & 2.86 & $1,638.74$ & -1.872 \\
\hline 14 & & 0.30 & $15,000,000.00$ & $3,000,000.00$ & $1,500.00$ & 2.57 & $1,472.57$ & -1.829 \\
\hline 15 & & 0.50 & $14,200,000.00$ & $2,840,000.00$ & $1,420.00$ & 2.47 & $1,415.27$ & -0.333 \\
\hline 16 & & 0.70 & $12,350,000.00$ & $2,470,000.00$ & $1,235.00$ & 2.15 & $1,231.92$ & -0.249 \\
\hline
\end{tabular}


By observing the results we can note that the buckling coefficients obtained in this study can be applied to plates having different dimensions but having the same ratio $\alpha$, i.e., the ratio of hole diameter to the loaded edge must be the same as those for which the buckling coefficients are proposed. The last column of Table 5 shows the values of differences between buckling stresses calculated using $K_{C}$ and those obtained from FEM analyses. As can be seen in the table errors are small, and good agreement is observed for the results obtained from both FEM and theoretical analyses.

\subsection{Boundary between thin and thick plates}

In order to investigate the range of thin and thick plates, plates having different dimension as given in Table 6 are investigated. The plates having dimensions of 2, 3, 4 and 5 times larger than the original plate have been investigated to find out the trend of change in border of thin and thick plates. The value of 0.2 is considered for $\alpha$ as already used for analyzing the plates from the viewpoint of thickness. The materials have been chosen as the same as already used in previous analyses.

From the results provided in Table 6 it can be inferred that by increasing the size of the plate the boundary for thick and thin plate is shifted. To have a better understanding of the trend of change a graph is provided in Fig. 15 by using the results obtained from finite element analysis employing ABAQUS. The abscissa is designated to the ratio of length of desired plate to that of the original plate studied in this article, which is denoted by $L / L_{0}$. On the other hand the vertical axis refers to change in the boundary between thin and thick plates, the thickness beyond which the plates fail due to materials yielding instead of buckling, which is presented by $t_{B} / t_{B 0}$ As can be seen from Fig. 15 there is a perfect linear relationship between increasing in dimensions of plate and the boundary shift. This boundary should be taken into account when the calculations of buckling loads of desired plates are done. Taking glance at Eq. (2) by which the critical stress is calcula-ted, the importance of mentioned boundary thicknesses can be noticed. As can be inferred from Eq. (2), the critical stress is inversely related to square of Poisson's ratio. The Poisson's ratio varies from 0.3 for thin plates, plates having the thickness smaller than the determined boundary thickness, to 0.5 for thick plates, those with the thickness greater than the boundary. Therefore, finding the boundary between thin and thick plate gains its importance as the critical stresses is a function of Poisson's ratio which is different for thin and thick plates.

Table 6

Verification of boundary between thin and thick plates

\begin{tabular}{|c|c|c|c|c|c|c|c|}
\hline NO & Dimensions, mm & Eigenvalue & Critical load, N & Stress, MPa & $L / L_{0}$ & $\begin{array}{c}\text { Boundary between } \\
\text { thick and thin plate, } \\
\text { mm }\end{array}$ & $t_{B} / t_{B 0}$ \\
\hline 1 & $\begin{array}{r}\text { Length }=200 \mathrm{~mm} \\
\text { Width }=100 \mathrm{~mm}\end{array}$ & $983,053.0$ & $98,305.0$ & 400.0 & - & 2.457 & - \\
\hline 2 & $\begin{array}{r}\text { Length }=400 \mathrm{~mm} \\
\text { Width }=200 \mathrm{~mm}\end{array}$ & $1,966,480.0$ & $393,208.0$ & 400.0 & 2 & 4.915 & 2 \\
\hline 3 & $\begin{array}{r}\text { Length }=600 \mathrm{~mm} \\
\text { Width }=300 \mathrm{~mm}\end{array}$ & $2,946,480.0$ & $883,994.0$ & 400.0 & 3 & 7.371 & 3 \\
\hline 4 & $\begin{array}{r}\text { Length }=800 \mathrm{~mm} \\
\text { Width }=400 \mathrm{~mm}\end{array}$ & $3,932,570.0$ & $1,573,028.0$ & 400.0 & 4 & 9.830 & 4 \\
\hline 5 & $\begin{array}{r}\text { Length }=1000 \mathrm{~mm} \\
\text { Width }=500 \mathrm{~mm}\end{array}$ & $4,914,370.0$ & $2,457,185.0$ & 400.0 & 5 & 12.286 & 5 \\
\hline
\end{tabular}

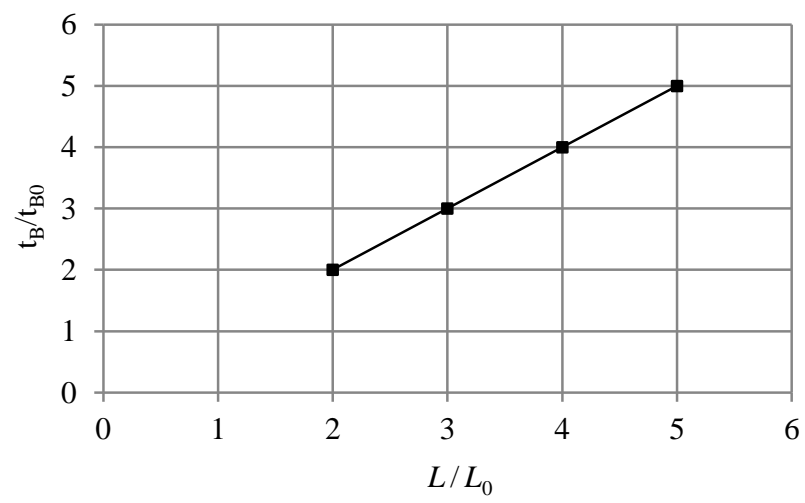

Fig. 15 Change in boundary between thin and thick plate

\section{Conclusions}

Study on buckling of plates with holes has demonstrated that thickness has a significant influence on buckling load and stress of plate. It has been shown that as the thickness of plate increases the buckling load and buckling stress increase by $\left(F_{c r 2}=F_{c r 1}\left(\frac{t_{2}}{t_{1}}\right)^{3}\right)$ and $\left(\sigma_{c r 2}=\sigma_{c r 1}\left(\frac{t_{2}}{t_{1}}\right)^{3}\right)$, respectively. Through this study buckling coefficients has been obtained for different thickness and hole size, by using Eq. (2) and stressed obtained from the analyses. To generalize the results the normalized hole size $\alpha=d / a$ was defined. Thereafter the obtained buckling coefficients were employed to calculate the buckling stress for plates having different dimension but same aspect ratio using Eq. (2). The obtained buckling stresses have been compared with those of obtained with FEM analyses performed by ABAQUS and provided in Table. 5. The comparison proved that there is good agreement so the proposed buckling coefficients can be employed to predict the buckling stresses of plates with holes. Another study that was performed during this study was to find the border between 
thin and thick plates based on yield stress and obtained critical stress. Its importance lies in the fact that the Eq. (2) is different for thin and thick plate as the Poisson's ratio changes from 0.3 for thin plates to 0.5 for thick plates.

\section{Acknowledgment}

This work is supported by National Research Foundation of Korea (NRF-2014R1A1A2056157).

\section{References}

1. William L.1998. Mechanical and thermal buckling behavior of rectangular plates with different central cutouts, Dryden Flight Research Center, NASA, USA.

2. Cristopher, D.M.; Schafer, B.W. 2009. Elastic buckling of thin plates with holes in compression or bending, ThinWalled Structures 47: 1597-1607. http://dx.doi.org/10.1016/j.tws.2009.05.001.

3. Pawlus, D. 2007. Critical static loads calculations in finite element method of three-layered annular plates, Civil and Mechanical Engineering 7(1): 21-33. http://dx.doi.org/10.1016/S1644-9665(12)60002-8.

4. Naik, R.T.; Moen, C.D. 2010. elastic buckling studies of thin plates and cold-formed steel members in shear, Department of Civil \& Environmental Engineering, Virginia Tech.

5. Levin, V.A.; Zingerman, K.M.; Vershinin, A.V.; Freiman, E.I.; Yangirova, A.V. 2013. Numerical analysis of the stress concentration near holes originating in previously loaded viscoelastic bodies at finite strains, International Journal of Solids and Structures 50: 20-21.

Available from Internet: http: // dx. doi. org/ 10.1016/j. ijsolstr. 2013.05.019.

6. Husam Al Qablan; Hasan Katkhuda; Hazim Dwairi 2009. Assessment of the buckling behavior of square composite plates with circular cutout subjected to in-plane shear, Jordan Journal of Civil Engineering 3(2): 184-195.

7. Shimizu, S. 2010. Tension buckling of plate having a hole, Thin-Walled Structures 45(10-11): 827-833. http://dx.doi.org/10.1016/j.tws.2007.08.033.

8. El-Sawy, K.M.; Nazmy, A.S. 2001. Effect of aspect ratio on the elastic buckling of uniaxially loaded plates with eccentric holes, Thin-Walled Structures 39: 983-998. http://dx.doi.org/10.1016/S0263-8231(01)00040-4.

9. Tom, Pollock. 1993. Introduction to Buckling, Dept. of Aerospace Engineering, Texas A\&M University, USA.

10. Rebecca Curtis, P.E.; Roger Till, P.E. 2008. Calculating the critical buckling stress for plates with one free edge under combined axial and flexural forces, Michigan Department of Transportation Construction and Technology Division, Technical report.

11. Gerard, G.; Becker, H. 1957. Handbook of structural stability- Buckling of flat plates, National advisory committee for aeronautics, New York University.
12. Jodoin, et al. 2012. Analysis of Buckling, Vol. III.

13. Mitao Ohga; Tsunemi Shigematsu; Kouichi Kawaguchi. 1995. Buckling analysis of thin-walled members with variable thickness, Journal of Structural Engineering 121: 919-924.

http://dx.doi.org/10.1061/(ASCE)07339445(1995)121:6(919).

14. Hong, G.M.; Wang, C.M.; Tan, T.J. 1993. Analytical buckling solutions for circular Mindlin plates: inclusion of in-plane pre-buckling deformation, Applied Mechanics 63: 534-542.

15. Tinh, Q.B.; Minh, N.N. 2011. Eigenvalue analysis of thin plate with complicated shapes by a novel mesh-free method, International Journal of Applied Mechanics 3(1): 21-46. http://dx.doi.org/10.1142/S1758825111000853.

16. Mohammadzadeh, B.; Noh, H.C. 2014. Use of buckling coefficient in predicting buckling load of plates with and without holes, J. Korean Soc. Adv. Comp. Struc 5(3): 1-7. http://dx.doi.org/10.11004/kosacs.2014.5.3.001.

\section{B. Mohammadzadeh, H.C. Noh}

\section{INVESTIGATION INTO BUCKLING COEFFICIENTS OF PLATES WITH HOLES CONSIDERING VARIATION OF HOLE SIZE AND PLATE THICKNESS}

S u m m a r y

Buckling analyses on plates with through-thickness holes are performed in order to find the buckling coefficient $K_{C}$ which depends on the geometrical condition of individual plates such as size of holes and thickness of plates. In order to generalize the results, $\alpha$ is introduced. It is observed that the buckling coefficient shows nonlinear trend in terms of the coefficient $\alpha$. The trend, however, is similar to each other for plates with different thickness, having plateau region in the intermediate values of alpha. The ratio of buckling coefficients of plates with holes to that of the plates without holes is revealed to be constant irrespective of the plate thickness. To verify the generality of buckling coefficients, plates with different dimensions from the original plates are analyzed. Buckling stresses by using the suggested buckling coefficients show good agreement with those obtained by numerical analyses and errors are small enough to be ignored.

Keywords: buckling; steel plate; through-thickness hole plates; buckling coefficient.

Received July 07, 2015

Accepted May 11, 2016 